\title{
AMENDMENTS
}

\section{Author Correction: The liberating force of ultrasound}

\author{
Roman Boulatov (1)
}

Correction to: Nature Chemistry https://doi.org/10.1038/s41557-020-00623-9, published online 29 January 2021.

In the version of this News \& Views originally published, in Fig. 1b, the text 'POEGMEA' should have read 'POEGMEMA'. At the bottom of Fig. 1c, in the black structure labelled 'POEGMEA', the opening bracket labelled ' $m$ ' should have appeared one bond to the left. Additionally, the penultimate sentence in the Fig. 1 caption incorrectly read 'POEGMEMA polymer chains are used in systems releasing active drugs by scission of both non-covalent and covalent bonds'; it should have read 'The two related polyacrylates bearing oligo(ethylene glycol) side chains - POEGMEMA and POEGMEA - enable release of active drugs by scission of non-covalent and covalent bonds, respectively' These errors have now been corrected.

Published online: 13 May 2021

https://doi.org/10.1038/s41557-021-00700-7

() Springer Nature Limited 2021

\section{Author Correction: The missing colours of chemistry}

Binuraj R. K. Menon iD

Correction to: Nature Chemistry https://doi.org/10.1038/s41557-020-00632-8, published online 29 January 2021.

In the version of this Comment originally published, the 'Selective memory' section on page 6 referred to 'Arabic alchemists'; it should have referred to 'alchemists in the medieval Middle East'. This has now been corrected.

Published online: 30 April 2021

https://doi.org/10.1038/s41557-021-00710-5

๑) Springer Nature Limited 2021

\section{Publisher Correction: Stereo- and regiodefined DNA-encoded chemical libraries enable efficient tumour-targeting applications}

Nicholas Favalli (D), Gabriele Bassi (D), Christian Pellegrino (D), Jacopo Millul (D), Roberto De Luca, Samuele Cazzamalli (D), Su Yang, Anika Trenner (D), Nour L. Mozaffari (D), Renier Myburgh, Mustafa Moroglu, Stuart J. Conway (D), Alessandro A. Sartori $\mathbb{D}$, Markus G. Manz $\mathbb{D}$, Richard A. Lerner, Peter K. Vogt $\mathbb{D}$, Jörg Scheuermann (iD) and Dario Neri (iD)

Correction to: Nature Chemistry https://doi.org/10.1038/s41557-021-00660-y, published online 8 April 2021.

In the version of this Article originally published, in Fig. 2e the stereochemistry of the linker in the Asp and Lys residues of compounds LFluo and LH were incorrectly shown as $(R)$; they should have been shown as $(S)$. An error in the linker structure also appeared in compounds 39 and 56 on page 53 of the Supplementary Information. In addition, the ELISA curves in Fig. 5c were incorrectly assigned to compounds 29 and 30; they should have been assigned to compounds $\mathbf{2 7}$ and $\mathbf{2 8}$, respectively. These corrections have now been made.

Published online: 8 June 2021

https://doi.org/10.1038/s41557-021-00742-X

(C) The Author(s), under exclusive licence to Springer Nature Limited 2021 